\title{
Vena Cava Thrombosis
}

National Cancer Institute

\section{Source}

National Cancer Institute. Vena Cava Thrombosis. NCI Thesaurus. Code C159323.

The formation of a thrombus in the vena cava. 